\title{
P02.83. Mindfulness meditation in community dwelling older adults with postherpetic neuralgia
}

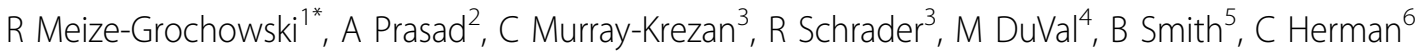 \\ From International Research Congress on Integrative Medicine and Health 2012 \\ Portland, Oregon, USA. 15-18 May 2012
}

\section{Purpose}

This pilot study compared usual care alone with usual care plus meditation in relation to anxiety, depression, pain, and quality of life in community-dwelling older adults with postherpetic neuralgia (PHN). PHN may occur after shingles, and has been described as one of the most intractable neuropathic pain disorders. Older adults develop PHN more often than younger adults. Mindfulness meditation, found to be beneficial in the management of some chronic pain conditions, has not been specifically examined in older adults with PHN.

\section{Methods}

Using a two-group pretest-posttest design with repeated measures, data were collected at entry to the study (Time 1), after a 2-week control period (Time 2), and 6 weeks later (Time 3). After Time 2 testing, participants were randomly assigned to usual care alone or usual care plus meditation. Daily pain diaries were kept by all participants for 8 weeks.

\section{Results}

The 27 study participants were between 55 and 90 years of age, with a mean of 72 years. Fifteen participants were female, and 12 were male. Fourteen participants were White, 11 were Hispanic, and 2 were American Indian. At entry to the study, 18 participants reported moderate or greater pain seven days per week due to PHN. Data analysis included repeated measures ANOVA for the three time periods. Although no statistically significant differences were found for time or interaction effects, trends indicating a favorable response to mindfulness meditation over time were identified in the majority of the outcome variables.

${ }^{1}$ College of Nursing, University of New Mexico, Albuquerque, USA Full list of author information is available at the end of the article

\section{Conclusion}

Participants were able to commit to the protocol for the duration of the study. The small sample size is a limitation; improvement in either group could be due to the natural course of PHN or even investigator attention. Future studies will include a sample size that is powered to detect significant differences at $\alpha=.05$.

\section{Author details}

${ }^{1}$ College of Nursing, University of New Mexico, Albuquerque, USA. ${ }^{2}$ Section of Integrative Medicine, School of Medicine, University of New Mexico, Albuquerque, USA. ${ }^{3}$ Clinical \& Translational Science Center, University of New Mexico, Albuquerque, USA. ${ }^{4}$ Center for Life, University of New Mexico, Albuquerque, USA. ${ }^{5}$ Psychology Department, University of New Mexico, Albuquerque, USA. ${ }^{6}$ Division of Geriatrics, School of Medicine, University of New Mexico, Albuquerque, USA.

Published: 12 June 2012

doi:10.1186/1472-6882-12-S1-P139

Cite this article as: Meize-Grochowski et al: P02.83. Mindfulness meditation in community dwelling older adults with postherpetic neuralgia. BMC Complementary and Alternative Medicine 2012 12(Suppl 1): P139.

Submit your next manuscript to BioMed Central and take full advantage of:

- Convenient online submission

- Thorough peer review

- No space constraints or color figure charges

- Immediate publication on acceptance

- Inclusion in PubMed, CAS, Scopus and Google Scholar

- Research which is freely available for redistribution 